\title{
Understanding the Role of Information Technology for Organizational Control Design: Risk Control as New Control Mechanism
}

\author{
Manuel Wiesche, Michael Schermann, and Helmut Krcmar \\ Boltzmannstr. 3, 85748 Garching, Germany \\ Tel.: +49 (0) 8928919532 \\ \{wiesche, michael.schermann, krcmar\}@in.tum.de
}

\begin{abstract}
Organizational control is one of the fundamental functions of management. Although controls come along with performance constraints, organizations rely on control mechanisms to direct attention, motivate, and encourage organizational members to act according to organizational goals and objectives. Managers build their decision on control design on the degree of knowledge about the value creation process and the predictability of the outcome. In this paper, we enhance a popular theoretical framework for organizational control design by enclosing IT-enabled controls. We explore the framework empirically in a multiple case study on Governance, Risk management, and Compliance information systems (GRC IS), a popular new trend in organizational control design. Our findings provide evidence that IT-enabled controls enable a new control mechanism, risk control, for situations with perfect knowledge about the transformation process and high ability to measure output. As research implication, we recommend an extension of organizational control theory to incorporate the effects of information technology on control design. As practical implication, we provide decision support for the selection of GRC controls, depending on situational factors and the expected value proposition. In sum, this research enhances the body of knowledge on organizational control design with a risk-based perspective.
\end{abstract}

Keywords: Risk Control, Organizational Control, Risk Management, Compliance, Governance, GRC, Uncertainty.

\section{Introduction}

Organizational control refers to management mechanisms to direct attention, motivate, and encourage organizational members to act according to organizational goals and objectives (Cardinal et al. 2004; Eisenhardt 1985; Lange 2008; Ouchi 1979; Tannenbaum 1962). The dominant model of organizational control design (Ouchi 1979) suggests certain control mechanisms, depending on the dimensions availability of outcome measures and knowledge of the transformation process. The framework allows managers to decide between input control (e.g. employee selection, training), behavior control (e.g., specific procedures for certain tasks), and output control 
(e.g. quality assurance). However, research criticizes the framework as too static (Cardinal et al. 2004), implementing wrong informal controls (Kirsch et al. 2002), and lacking performance and integration (Liu et al. 2010).

In this paper, we find that the existing organizational control mechanisms decision framework omits the rising uncertainty in organizations and the IT-enabled possibilities of automation and mass-data processing. This leads to the following research question: How does Information Technology affect organizational control design? To answer this question, we derive two hypotheses from IS and control literature to reveal the effects of IT on organizational control theory. We evaluate our hypotheses in practice through analyzing the current trend of IT-enabled organizational control design, called Governance, Risk management and Compliance (GRC). We argue that IT enables a new control mechanism for situations with perfect knowledge about the transformation process and high ability to measure output. We propose a new control mechanism, based on extensive knowledge about business processes and management's ability to gather dubious information early enough to permit time for countermeasures.

The remainder of this paper is organized as followed: The next section gives an overview over the current state of GRC IS. The following section reviews prior literature on organizational control. Subsequently, hypotheses are presented, followed by the description of the research methodology and an overview of the empirical results. The paper ends with a discussion of the results, implications for research and practice, and concluding remarks.

\section{Current State of GRC IS}

Looking at the current practical developments in control design, the Sarbanes-Oxley Act (SOX) in 2002 and its equivalent regulations in other nations (Wiesche et al. 2011) caused the development of new, IT-enabled controls which can be found under the label of GRC IS, which today is certainly prominent in practice (Dittmar 2007; Parry 2004). For this research, we understand GRC as the integrated Governance, Risk, and Compliance perspective on organizational controls for management (Volonino et al. 2004). GRC IS provide a variety of controls ranging from procedures to monitor user access to information systems, to monitor process performance and provide enterprise-wide risk management. Besides controls, GRC also implements mechanisms to report on compliance and to manage existing business processes (Heiser 2010).

In the disciplines of audit and consulting, GRC is discussed as the automation and observation of controls (Doyle et al. 2007; Parry 2004). Research furthermore focuses on control deficiencies (Ashbaugh-Skaife et al. 2008) and the effects on the financial outcome (Doyle et al. 2007). Research on GRC in governance literature includes the IT-business alignment and adequate and efficient coordination of tasks (Chan 2002). Compliance-related discussions rather focus on effective controls (Jensen 1993), cost reduction (Wagner et al. 2006) and the integrity of information systems (Volonino et al. 2004). Literature on software-based control discusses effectiveness of measures (Nolan et al. 2005). Software development companies selling GRC solutions focus on 
segregation of duty and process control (Heiser 2010). From an Information Systems perspective, research on GRC IS focuses on frameworks for the design of GRC IS (Beneish et al. 2008; Racz et al. 2010).

\section{Theoretical Foundation}

Before elaborating on control mechanisms and situational conditions, it is helpful to recapitulate organizational control theory. Following Tannenbaum's understanding of organizational control as interpersonal influence relations within organizations, organizations are arrangements of individual human interactions (Tannenbaum 1962). Control enables idiosyncratic behavior and compliance with the strategic plan and is therefore fundamental for any organization. For a broad summary of the various understandings of organizational control refer to Lange (2008) and Walsh et al. (2006). Although there has been criticism (Eisenhardt 1985; Nilakant et al. 1994), Ouchi's organizational control framework (1979) is still the most prominent in current research (Nixon et al. 2005) and will be introduced in the following.

\subsection{Different Control Mechanisms}

To control relations within organizations, several control mechanisms exist. All control mechanisms are based on two underlying control strategies (Lange 2008). The first, formal control strategy forces coercion and manipulates rewards and sanctions. This control strategy requires explicit, formal rules, procedures, and policies to both monitor and reward organizational performance. This requires the continuous collection and aggregation of information. The second, informal control strategy aims at minimizing the divergence of personal and company goals. To establish an internal, value based control strategy, the principal has to define norms, values, and culture to ensure goal congruence with the agent. Using e.g. careful recruitment and companywide beliefs, and norms, the principal can align the agent's behavior to suit the organization's goal. The following four control mechanisms are implementations of the two control strategies (Lange 2008).

When implementing output control mechanisms, the principal monitors the agent's achievements at the end of the given tasks. The monitoring of the output of the value creation process implements the formal control strategy through analyzing the output of the performed tasks. Implementing output control requires a clear understanding of the results of the value creation process and the ability to evaluate the outcome (Das et al. 2001; Ouchi 1979).

Behavior control implements control mechanisms that help the principal to evaluate the agent's behavior. It implements the formal control strategy through evaluating the tasks that are performed by the employee on appropriateness and alignment with the overall strategy. Behavior control requires knowledge of the transformation process and understanding of the involved resources (Das et al. 2001; Ouchi 1979). 


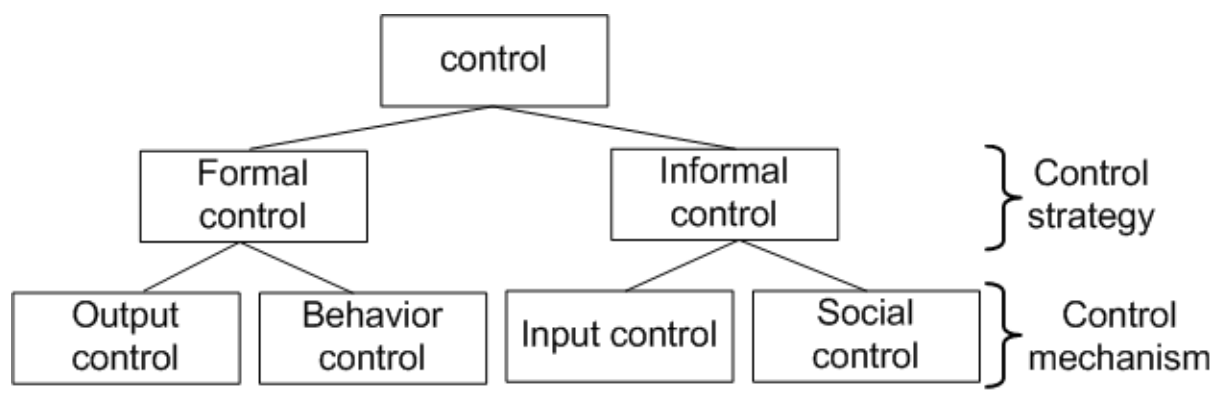

Fig. 1. Control Typology

Input control refers to the selection of appropriate agents who reveal goal congruence with the principal. Input control is a way to implement the strategy of socially aligning goals through selecting good employees who share goals that suit the organizational strategy. Implementing input control requires the ability to measure the agent's alignment with the principal's goals and furthermore the existence of agents who have the required characteristics (Ouchi 1979).

Social control refers to the development of shared beliefs, values and norms through guidelines and top management commitment. Implementing social control requires the ability to influence the agent's alignment with the principal's goals through guidelines and code of conducts (Ouchi 1979). For further examples for control mechanisms refer to Kirsch (1997) and Lange (2008).

In the following section we will introduce factors, influencing the decision for either control mechanisms. For now, we assert that behavior control is effective but output control the more efficient choice (Ouchi 1979). Management should commonly prefer behavior control to output control due to the ability to implement the right countermeasures before the end of the value creation process. Input control requires the lowest operational costs and should be chosen if the turnover within the organization is low (Ouchi 1979). Due to phenomena like the ongoing war for talent (Chambers et al. 1998) it might sometimes not be possible to either design effective input controls or find the right candidates.

\subsection{Decision Model for Control Mechanisms}

To decide which control mechanism suits the current organizational decision situation, the underlying information characteristics of the agency situation are important (Ouchi 1979). Depending on the characteristics of the situation, the principal can decide which control mechanism to use. Literature suggests that the ability to design certain controls depends on the principal's knowledge of the transformation process and principal's ability to measure the result of the value creation process early or at a later stage of the process (Figure 2).

The dimension knowledge of the transformation process refers to the principal's knowledge how the value creation tasks have to be performed by the agent (Ouchi 1979). If the principal exactly knows which tasks the agent has to accomplish, the knowledge of the transformation process is high. When the principal does not know, 
which factors influence the value creation and therefore the necessary tasks the agent has to perform, the knowledge of the transformation process is low.

The dimension ability to measure refers to the principal's ability to determine the result of a certain task. While literature agrees on knowledge of the transformation process, the second dimension is discussed controversially: It is argued that the suggested dimension output lacks the integration of uncertainty and controllability as fundamental factors influencing the decision (Eisenhardt 1985; Nilakant et al. 1994). Especially modern, complex organizations struggle with uncertainty about the outcome of the value creation process (Weick et al. 2007). Decisions are based on uncertain information, e.g. forecasts or assumptions of employees. Complexity, interdependencies and quick changes in market and other surrounding areas lead to non-predictability of the process outcome and its market success.

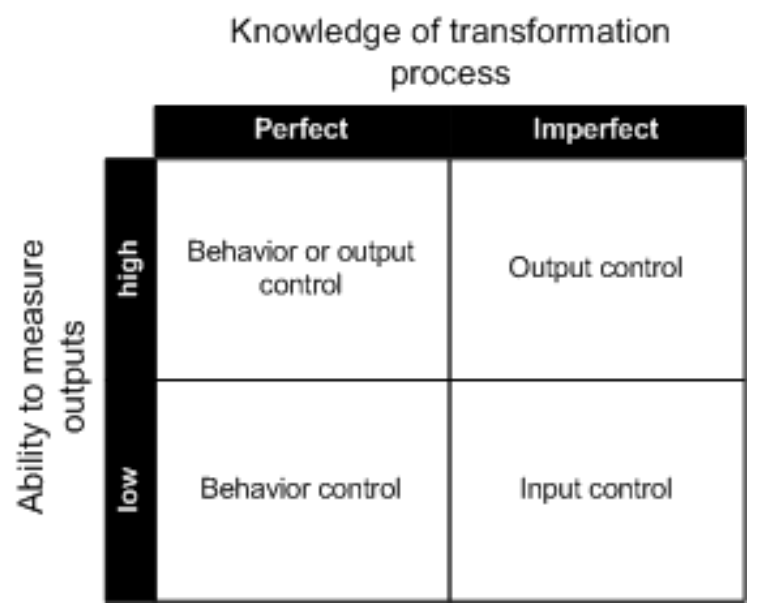

Fig. 2. Organizational Control Framework (Ouchi 1979)

The author argues that the developed dimensions provide decision support for specific managerial situations (Ouchi 1979). Although this is true for three quadrants of the matrix (Figure 2), the framework does not provide decision support for situations with high ability to measure output and perfect knowledge of the transformation process, e.g. the suggested "Apollo program". Although the author suggests that in this situation, "the lower cost alternative will be preferred" (Ouchi 1979), the framework lacks decision support for the situation with high ability to measure output and perfect knowledge of the transformation process:

"We can completely specify each step of the transformation process which must occur in order for a manned capsule to get to the surface of the moon and back to earth, thus giving us the possibility of behavior control. However, we also have an unambiguous measure of output: either the capsule gets there and back, or it doesn't. Thus we have a choice of either behavior control or of output control." (Ouchi 1979) 


\section{Effects of IT on Organizational Control}

Since GRC IS, as the current trend in organizational control design, focuses on the integration of IT, we will discuss the effects of IT on organizational control design in the following.

IT-enabled control mediates direct supervision of the agent through electronic surveillance and therefore adds to management's knowledge on the value creation process. With the evolving of ERP systems in companies, a new form of control emerged: the panoptic control. The panoptic control refers to what Bentham suggested for prison design in the early nineteenth century (Foucault 1977). The prison is built with a central tower that enables guards to see all prisoners from one position. This type of visibility creates an indirect situation of ubiquitous inspection and surveillance (Clegg 1998). Due to its complexity and the required high effort of manual monitoring, this concept could not be transferred on organizational control design. However, the development of integrated IS such as ERP systems enables such panoptic controls (Quattrone et al. 2005). Since IT is integrated in almost every employee's task, continuous monitoring like within panoptic control becomes feasible for organizational control design. A study at an Asian hospital confirms that implementing ERP software enables panoptic control (Sia et al. 2002). Similarly to the panoptic prison, all business processes are automatically monitored, gaining management access to all process steps at any time. The authors observe that panoptic control was automatically added as an additional layer on top of existing controls. Introducing ERP systems enables management to take a closer look at all IT-related behavior, performed by their employees. Hence, IT-enabled control adds to management's knowledge of the transformation process.

There has been extant research on the management of organizational processes. Starting with business process reengineering (BPR) as the fundamental redesign and radical new development of the whole organization or the core processes (Hammer et al. 1993), process management evolved to a less radical and more focused management of organizational processes (Davenport 1993). Literature finds that one of the major reasons for process management is the documentation and visualization of existing processes (Gunge 2000). Introducing IT-enabled control extends this documentation perspective for organizational controls. With the combination of the knowledge on the necessary value creation tasks and IT-enabled control, management is able to closely monitor and control the organizational value creation process. Hence, IT enables the visibility of company processes and creates transparency among procedures and tasks. This leads to the following hypothesis, which adds to organizational control theory:

Hypothesis 1: The adoption of IT increases the knowledge of the transformation process in organizational control situations.

IT-enabled automation allows the processing of mass data. Using IT enables the principal to gather and evaluating high amounts of data efficiently (Orlikowski 1991). Focus can be laid on either value creation related tasks or not value creation related behavior. 
Since management is able to evaluate not business process related behavior, non-compliant behavior can be recognized earlier (Fisher 2007). The automatic and intelligent pre-selection through thresholds and alerts helps management gather dubious information early enough to permit time for countermeasures. Before the introduction of IT-enabled controls it was not efficient to react on every vague, uncertain possible threat: organizational decision makers focused on precise information (Ansoff 1975). IT-enabled transparency within the organization allows the collection of specific information with reasonable effort. With the introduction of mass data processing and automation in control design, management can explore dubious, but vague information at an early stage and therefore develop better planned countermeasures.

IT-enabled data processing enables realtime and background data processing. Management can monitor their employees through automated IS which run in the background of the employee's working station. Hence, IT-enabled control does not reduce organizational performance, gives management easy access to vague failure data, and allows the implementation of early warnings (Ansoff 1975; Weick et al. 2007). Therefore, using IT to support organizational control mechanisms increases the amount of data that can be processed. Accordingly, the following hypothesis is proposed:

Hypothesis 2: Using IT to support organizational control mechanisms increases management's ability to measure output.

In sum, the reviewed literature suggests that the impact of IT on organizational control design affects especially situations with high ability to measure output and perfect knowledge of the transformation process. IT allows new controls through its ability to create transparency and process mass data. In the following, we will provide empirical evidence, revealing the need to extend the existing organizational control decision framework (Figure 2).

\section{Research Methodology}

For scrutinizing the theoretical foundation of IT-enabled controls, a multiple case study was chosen (Yin 2008). This approach seemed appropriate to understand how GRC IS influences control design and its impacts on control efficiency. We conducted qualitative data analysis (Strauss et al. 1998) on 14 expert interviews.

We derived hypotheses from literature before analyzing the case data, not to imitate quantitative research, but to test these hypotheses from various perspectives on the topic of GRC. This approach allows theory building (sampling logic) and model development (generalization) (Yin 2008). To develop the model we built on existing research on organizational control and derived additional influencing factors.

Since this case builds upon existing theory, the focus of selecting comparison groups for theory building was on maximizing diversity (Glaser et al. 2001). Maximizing diversity increases the possibility of finding different and varying data belonging to one sample. The differences support category building and summing up the data. 


\subsection{Sampling and Data Collection}

To achieve highest diversity, a broad view on GRC was chosen, including all perspectives that relate to IT-enabled controls within organizations (Table 1). The professions and disciplines relevant for this research included audit, consulting, governance, compliance, risk management, IT, and users in terms of GRC IS.

Table 1. Perspectives on GRC Controls and Interviewees

\begin{tabular}{|c|c|c|c|c|c|}
\hline Perspective & Expert ID & Language & Length & Background & Experience \\
\hline Audit & Auditor 1 & German & $1 \mathrm{~h} 04 \mathrm{~min}$ & Business & 8 years \\
\hline Audit & Auditor 2 & German & $1 \mathrm{~h} 04 \mathrm{~min}$ & Accounting & 4 years \\
\hline Consulting & Consultant 1 & English & $1 \mathrm{~h} 25 \mathrm{~min}$ & Business & 10 years \\
\hline Consulting & Consultant 2 & German & $0 \mathrm{~h} 59 \mathrm{~min}$ & Audit & 23 years \\
\hline Governance & Governance expert 1 & English & $1 \mathrm{~h} 02 \mathrm{~min}$ & Audit & 16 years \\
\hline Governance & Governance expert 2 & English & $1 \mathrm{~h} 15 \mathrm{~min}$ & Compliance & 10 years \\
\hline Usage & Company expert 1 & German & $0 \mathrm{~h} 51 \mathrm{~min}$ & $\begin{array}{l}\text { Computer } \\
\text { Science }\end{array}$ & 6 years \\
\hline Usage & Company expert 2 & German & $1 \mathrm{~h} 13 \mathrm{~min}$ & $\begin{array}{l}\text { Computer } \\
\text { Science }\end{array}$ & 12 years \\
\hline Compliance & Compliance expert 1 & English & $1 \mathrm{~h} 07 \mathrm{~min}$ & Finance & 16 years \\
\hline Compliance & Compliance expert 2 & German & $1 \mathrm{~h} 49 \mathrm{~min}$ & Finance & 22 years \\
\hline Software & IT professional 1 & German & $1 \mathrm{~h} 22 \mathrm{~min}$ & Accounting & 17 years \\
\hline Software & IT professional 2 & German & $1 \mathrm{~h} 59 \mathrm{~min}$ & $\begin{array}{l}\text { Computer } \\
\text { Science }\end{array}$ & 11 years \\
\hline Risk & Risk manager 1 & German & $1 \mathrm{~h} 04 \mathrm{~min}$ & IS & 14 years \\
\hline Risk & Risk manager 2 & English & $1 \mathrm{~h} 02 \mathrm{~min}$ & $\begin{array}{l}\text { Risk } \\
\text { Management }\end{array}$ & 3 years \\
\hline
\end{tabular}

Since the different perspectives on GRC provide different focal points, we interviewed two experts from each perspective using convenience sampling. We met experts on GRC workshops in Germany and used professional discussion groups and blogs to identify potential respondents. All experts had between 3 and 23 years of experience in their profession; the average experience was more than 12 years. Although having different backgrounds, we grouped the expert's perspective according to their current job description (Table 1). We conducted the interviews using guidelines with semi-structured questions, including questions about GRC systems as well as questions regarding the developed IT-enabled controls. We tailored the interview guidelines to the hypotheses on the impact of IT control design. The interviews were open-ended phone interviews, the interview with compliance expert 2 was held faceto-face. We conducted nine interviews in German. The interviews with the governance and risk experts, compliance expert 1, and consultant 1 were held in English. 


\subsection{Data Analysis Procedure}

We tape-recorded, transcribed, and anonymized all interviews. We integrated the transcripts from the 14 interviews into a hermeneutic unit comprising 67,761 words and 58 pages of text using the software ATLAS.ti. The coding procedure was conducted following Glaser and Strauss' (2001) guidelines. First, the first author read and coded the interview transcripts line by line, using phrases from the transcripts that describe the phenomenon (open coding). Similar he tagged phenomena with the same phrase. This resulted in a list of 129 codings and 563 phrases. Following the coding by the first author, the second author likewise coded the transcripts independently. We discussed and agreed on the differing codes. In the next iteration (axial coding), we grouped the developed phrases to concepts. We put the derived concepts in coherence and then aggregated them regarding their effect on control.

\section{Results}

Controls in the context of GRC range from segregation of duty to policies and code of conduct. Prominent controls include behavior control mechanisms, referred to as process control. This incorporates the automation of internal control management for SOX-compliance as well as similar requirements and integration with risk management solutions. GRC incorporates further behavior control to monitor certain organizational risks with the integration of various participants and stakeholders. Experts gave several examples ranging from the energy sector to risk management solutions for IT companies, providing automated testing of controls. Further, ethical guidelines and codes of conduct exist and provide examples of social control mechanisms. In terms of output control, existing quality assurance solutions were integrated in the organization's GRC portfolio. Such controls are often implemented too late in the value creation process and therefore meet only regulatory compliance aspects. In the context of ERP solutions, the most prominent control is segregation of duty, called access control. Access control includes automation of end-to-end access and authorization management with strong integration within the access control solutions. Such controls can be implemented early in the organizational value creation process and provide first insights on fraud or other undesirable behavior. Controls like access control are enabled by IT, making it possible to process masses of data in real time.

"With GRC concepts, companies can implement controls which [...] support the early processing of information and providing information on possible company risks which might be blurred, but if ignored might result in serious to the organization." (Governance expert 1)

\subsection{The Role of IT in Increasing Knowledge of the Transformation Process}

An aspect which persistently appeared in the study was the ability to create transparency through ubiquitous controls, which run in background of existing IS. The different GRC perspectives reveal certain reasons for creating transparency. From an audit and compliance perspective, transparency accelerates audits and therefore reduces costs. Practitioners actually operating GRC solutions use transparency for decision support and compliance reasons. From the IT-perspective, the main reason was 
for decision support. The functional units report on their situation and management uses this information as basis for their decisions. Therefore, this information needs to be reliable. Before the development of IT-enabled controls, management had to rely on their input and social control mechanisms, not guaranteeing reliable results. With the development of IT-enabled controls, management is able to verify the given information and to equally compare different reports. Consistent with hypothesis 1 , interviewees argued that with IT-enabled controls, management can enhance knowledge of the transformation process:

"Management had to rely [on] reports and estimations with different quality and hierarchical level from various functions across the organization. At the end of the day, they had to decide [...] based on this information. The new approach enables management to have transparency through reporting structures and work tasks. I am convinced that it creates transparency and better knowledge of the employee's tasks." (IT professional 2)

From management perspective, this issue becomes even clearer. Before the implementation of IT-enabled control, management had to rely on their employee's engagement. Organizations were not able to know about all tasks performed on each hierarchical level. Therefore, they had to trust their employees and could only monitor the results at a reasonable level of costs. Automated, IT-enabled control mechanisms are able to process high amounts of data and provide information in real time. This enables management to get information on certain, maybe critical processes with reasonable efforts and supports hypothesis 1 .

"As a manager, you should know how your company works. [...] He has to know which tasks have to be performed to create a certain value. The implementation of GRC systems helps him to gain this knowledge context-specific [...] and gain information [to] found his decisions on." (Company expert 2)

From governance perspective, governmental regulations and the eager to found decisions on good data motivate management to define certain rules and procedures to provide this information. Management requests real time information on the risks, the organization is currently facing. This knowledge is gained from risk management at the operational level of the organization. Therefore the organization needs transparency from a top-down perspective. Especially for performance based controls it is important to develop integrated controls with similar measures.

Extending the process oriented value creation perspective, GRC enables optimization of the companies value creation tasks. Consultant 1, an interviewee with more than 20 years of experience in the field of IT consulting, argues that GRC is the natural successor of process management. Historically, IS design moved from mainframe to functional computing. Following that, the integrated process perspective, BPR and business process management (BPM) arose, enabling more control for management. The last years revealed serious shortcomings in this process oriented ERP based solution. SOX and other regulatory guidelines demanded formal aspects, sometimes questioning the usefulness of compliance rules and organizational benefit. The expert argues that GRC enables a new focus on business process optimization from a control perspective. The new trend of GRC controls helps companies meet this new type of 
requirements and increases management's knowledge of their value creation processes. Other experts confirm this argument, claiming that process control increase transparency and therefore increase the knowledge of the transformation process.

"Beyond governance and legal issues, [with the rise of GRC] there is a trend towards process optimization. It enables companies to directly optimize their portfolio and their internal structures." (Consultant 2)

"Process control applications optimize [...] business operations and help ensure compliance and mitigate risk by centrally monitoring key controls for business processes and cross-enterprise IT systems." (Risk expert 2)

Overall, the study illustrates the hypothesis that IT-enabled controls increase the knowledge of the transformation process. There are various reasons for creating transparency, but they all lead to the aim that the principal enhances his knowledge on the tasks performed by the agent and therefore the knowledge on the transformation process.

\subsection{The Role of IT in Enhancing Management's Ability to Measure Output}

Regarding hypothesis 2 , the study results revealed clear evidence that IT-enabled controls increase the ability to integrate weak signals. In organizations, there are often enough warnings that, if correctly interpreted, could prevent certain negative outcomes from happening. To understand why these warnings are often ignored, the existing control mechanisms give an understanding of this shortcoming (figure 3). Input and social controls do not provide reliability on certain happenings. Output control provides this reliability, but too late to implement correcting measures on this specific output to prevent the negative outcome. In a setting of outcome certainty, where all outcome-influencing factors are known and determinable, process control enables reliability on the desired outcome.

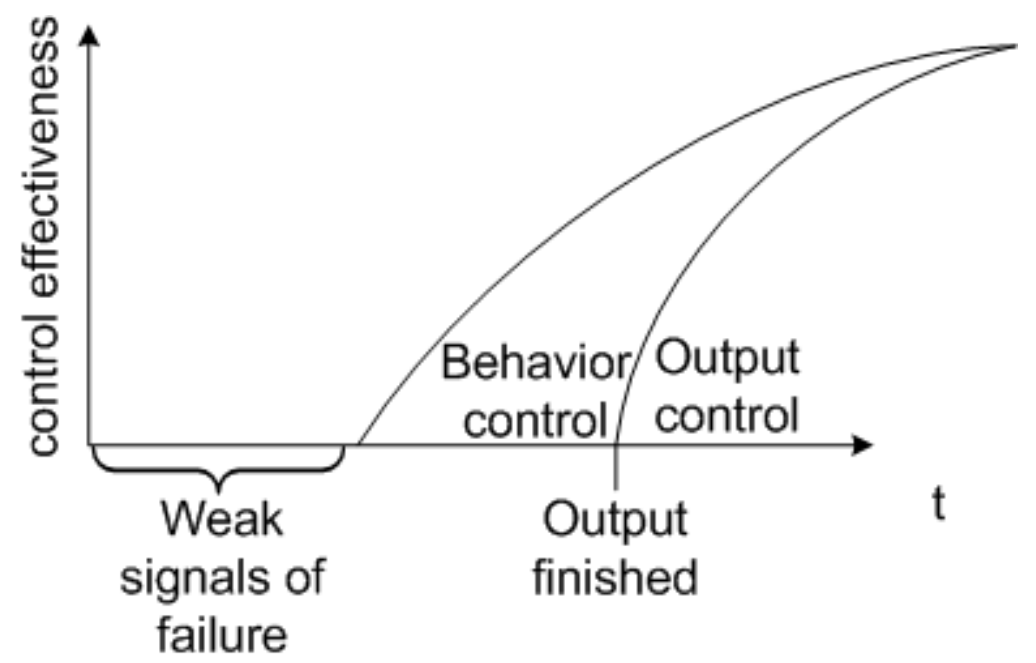

Fig. 3. Temporal Perspective on Control Mechanisms 
However, today's organizational settings become more complex and intricate and it is often impossible to monitor all influencing factors and control the necessary tasks. Although there has always been early information on possible negative outcomes, there was hardly any possibility to examine all indicators and derive preventing measures. The implementation of IT-based controls enables management to continuously monitor and rate weak signals that possibly lead to negative outcomes. Automation helps both, mass data processing and reduction of reaction time.

"[...], whistle blower mechanism can be automated, in addition to improving the amount of data processed within GRC solutions." (Compliance expert 1)

„So, companies would surely not document [transparency] with such detail and rigor, if there were no governmental regulations, forcing them to provide evidence." (Auditor 1)

This indication for the second hypothesis is further supported by arguments from the interviewees. Although there are various control mechanisms, the interviewees implicitly ranked their examples according to certain criteria. The experts claimed that control quality depends on control effectiveness. Deepening this argumentation, the study reveals that control effectiveness depends on two factors: point in time and certainty. Ideal controls would be applied early in the organizations value creation process and the effects of the controls would be entirely clear. Since there are no such controls, the experts stated that the tradeoff is either late usage or high uncertainty. In some cases (by the experts referred to as process control), the certainty is relatively high and it can be done early in the value creation process. As soon as there is higher uncertainty, the controls can either just be at the final product or service (quality management) or early with high effort and some uncertainty on the effects of the situation and possible controls (e.g. access control).

„You generally develop various controls. [...] Firstly, access controls (technically, reporting tools) which give an overview on the situation. Secondly, you develop guidelines for your employees and monitor that. Thirdly, you have to measure your results. "(Consultant 2)

\section{Discussion}

This study was motivated by the need to improve the understanding of the value proposition of IT-enabled control on organizational control design. We used the prominent example of GRC IS to show that IT-enabled control reveals new perspectives on organizational control design.

Based on the study results, we propose a new control mechanism to support an early anticipation of potential future happenings that endanger the outcome of the value creation process. It enables fast reactions to early warnings that threaten organizational success, the reduction of trust within control relationships and in combination with legal regulations improves the outcome certainty of the value chain. 


\subsection{IT Enables Organizational Controls}

The results confirm the assumption that in today's heterogeneous organizational environment a combination of various control mechanisms is necessary (Meiselman 2007; Orlikowski 1991). Especially auditors and consultants confirm that there are different GRC IS application contexts. These different goals imply different expectations and results. Management can decide between various controls, depending on the underlying organizational situation (Liu et al. 2010). The results furthermore reveal that management increasingly relies on IT-enabled controls.

As presumed above, the found IT-enabled controls do not fit in the described classifications in literature (Table 2). As behavior and output control can only implemented within the value creation process, IT-enabled controls are implemented without clear connection to these pure functional process but rather with an object oriented perspective. Since input and social control do focus on the organizational unit but are informal, the found IT-enabled controls cannot be classified within the existing frameworks.

Table 2. Classification of control types with new type risk controls

\begin{tabular}{|c|c|c|c|c|c|}
\hline $\begin{array}{c}\text { control } \\
\text { mechanism }\end{array}$ & type & $\begin{array}{l}\text { organizational } \\
\text { integration }\end{array}$ & strengths & weaknesses & $\begin{array}{l}\text { necessary } \\
\text { conditions }\end{array}$ \\
\hline $\begin{array}{l}\text { input } \\
\text { control }\end{array}$ & $\begin{array}{l}\text { in- } \\
\text { formal }\end{array}$ & $\begin{array}{l}\text { organizational } \\
\text { unit }\end{array}$ & $\begin{array}{l}\text { - low supervision } \\
\text { costs } \\
\text { - reliability due to } \\
\text { goal congruence }\end{array}$ & $\begin{array}{l}\text { - high level of trust } \\
\text { necessary } \\
\text { - highly qualified } \\
\text { agents necessary }\end{array}$ & $\begin{array}{l}\text { - availability of } \\
\text { qualified agents } \\
\text { - low turnover }\end{array}$ \\
\hline $\begin{array}{l}\text { social } \\
\text { control }\end{array}$ & $\begin{array}{l}\text { in- } \\
\text { formal }\end{array}$ & $\begin{array}{l}\text { organizational } \\
\text { unit }\end{array}$ & $\begin{array}{l}\text { - low setup costs } \\
\text { - no supervision } \\
\text { costs } \\
\text { - suits unknown } \\
\text { situations } \\
\end{array}$ & $\begin{array}{l}\text { - high level of trust } \\
\text { necessary } \\
\text { - hard to evaluate } \\
\text { - unreliable effects }\end{array}$ & $\begin{array}{l}\text { - ongoing } \\
\text { trainings } \\
\text { necessary } \\
\text { - continuity } \\
\text { - low turnover }\end{array}$ \\
\hline $\begin{array}{l}\text { output } \\
\text { control }\end{array}$ & formal & $\begin{array}{l}\text { functional } \\
\text { process }\end{array}$ & $\begin{array}{l}\text { - low costs of } \\
\text { supervision } \\
\text { - unambiguousness } \\
\text { - clear scale of } \\
\text { measurement }\end{array}$ & $\begin{array}{l}\text { - requires full know- } \\
\text { ledge on process output } \\
\text { - point in time of } \\
\text { measurement might be } \\
\text { too late }\end{array}$ & $\begin{array}{l}\text { - concrete } \\
\text { definition of value } \\
\text { creation } \\
\text { - ability to } \\
\text { measure output }\end{array}$ \\
\hline $\begin{array}{l}\text { behavior } \\
\text { control }\end{array}$ & formal & $\begin{array}{l}\text { functional } \\
\text { process }\end{array}$ & $\begin{array}{l}\text { - possibility to } \\
\text { change direction } \\
\text { during the process } \\
\text { - monitor agent's } \\
\text { task performance }\end{array}$ & $\begin{array}{l}\text { - high supervision costs } \\
\text { - reduces task } \\
\text { performance } \\
\text { - no clear measurement } \\
\text { scale }\end{array}$ & $\begin{array}{l}\text { - transformation } \\
\text { process must be } \\
\text { known } \\
\text { - behavior needs } \\
\text { to be measureable }\end{array}$ \\
\hline $\begin{array}{l}\text { risk control } \\
\text { (IT-eabled) }\end{array}$ & formal & $\begin{array}{l}\text { organizational } \\
\text { unit }\end{array}$ & $\begin{array}{l}\text { - early warning of } \\
\text { success threats } \\
\text { - interpreting weak } \\
\text { signals }\end{array}$ & $\begin{array}{l}\text { - high degree of } \\
\text { interpretation } \\
\text { - mass of information } \\
\text { - high costs }\end{array}$ & $\begin{array}{l}\text { - business } \\
\text { intelligence } \\
\text { - mass data } \\
\text { processing }\end{array}$ \\
\hline
\end{tabular}

\subsection{Introducing an IT-Enabled Control Mechanism: Risk Control}

The results reveal that IT enables new and fundamental controls within organizational control design. Since these controls combine characteristics that cannot be found in literature, we propose a new control mechanism called risk control. The controls introduced by the GRC experts, e.g. information systems for access control and risk management, are characterized by their focus on organizational unit rather than functional processes and allow implementing early warning systems to interpret ex-ante 
signal before incidents occur. Due to integration of IT, risk controls can process a high amount of data from various sources within the organization.

Risk control refers to the principal's early understanding of the uncertain, surprising, or non-assessable future happenings that endanger the outcome of the value creation process. As seen in the current approaches in practice, organizations use risk management to gain transparency, interpret early warnings and hence provide decision support. Using IT-enabled risk management, principals can control situations with high knowledge of the transformation process and high ability to measure output.

Risk control implies the tedious collection of high amounts of data and the careful analysis of this data with respect to signals of organizational failure. It is useful in vital and complex environments. It enables organizations to react early and possibly prevent major negative consequences at an early stage of the process (Ansoff 1975). It turns organizational control from reactive to proactive actions. Risk control allows performance-steadiness through ubiquitous monitoring of agents. It is based on effective risk management and IT support. Risk management allows the prediction of strategic surprises and threats to value creation processes (Ansoff 1975). This is possible through the integration of IT in the organizational control design. IT enables data collection across various functions at a reasonable amount of time and costs. To create resilience and prevent negative surprises, risk control provides early help in uncertain environments. The study reveals several control mechanisms that can be applied in situations with low outcome certainty and high knowledge of the transformation process. Access control, information systems for risk management or whistle blowing are examples for risk control mechanisms.

Although risk controls create transparency about organizational units and allow exante management of possible threats, they have the disadvantage of being cost intensive and interpretation dependent.

\subsection{Placing Risk Control in the Organizational Control Framework}

Existing literature on organizational controls does not provide decision support on control design for high knowledge of the transformation process and high ability to measure output (Ouchi 1979). The author uses additional indicators (costs) to suggest the most suitable control mechanism. The suggested control mechanism risk control uses IT to enable early information retrieval on a wide data basis but needs both, high ability to measure outputs and perfect knowledge of the transformation process (figure 4). Within the suggested decision framework (Ouchi 1979), the suggested control fits in the upper left corner with perfect knowledge of the transformation process and high ability to measure output. Its characteristics of using automation and mass data processing allow handling high amounts of data at an early point in time. It is further characterized by processing not only process related data, as it was characteristic for formal controls before, but allows integrating data relating to specific organizational units. Hence, the suggested risk control is the most suitable control mechanism for organizational situations with perfect knowledge of the transformation process and high ability to measure output. 


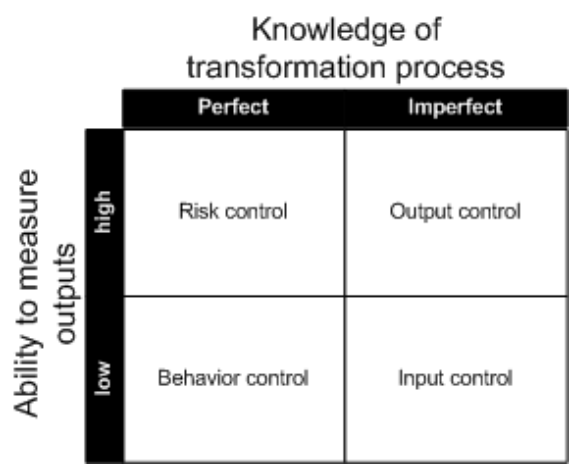

Fig. 4. Adopted Organizational Control Framework (Ouchi 1979)

\subsection{Implications and Limitations}

This research contributes to organizational control theory by integrating the effect of IT-enabled controls on organizational control design. We explain the benefits from automation and transparency through implementing IT-enabled controls within GRC IS. We propose risk control as a new control mechanism, incorporating weak signals within organizational control. Based on the assumption of higher goal incongruence and performance ambiguity, we argue that risk control mechanisms help to identify weak signals and prevent future threats to the organization. The adopted organizational control framework gives additional decision support for designing organizational controls through being the optimal alternative for situations with high ability to measure output and perfect knowledge of the transformation process. Within GRC IS, risk control is frequently implemented, e.g. through information systems for access control and risk management.

However, there are several limitations to take into account. First, it should be conceded that this study is based on only 14 interviews. Although it's exploratory nature and the aim of maximizing diversity allows certain broadness at the expense of depth, selecting only two experts from each GRC perspective could bias the findings through their personal opinion or specific experience. Although we used a broad sample from various organizations, it might be possible that the suggested concept of risk control is not suitable in all organizational settings. Especially in settings of emerging organizations or loose structures (Cardinal et al. 2004), risk controls have to be explored. Furthermore, we might have overlooked additional GRC stakeholders and hence additional value propositions.

In addition, although being the most obvious, organizational control theory might not be the appropriate theoretical lens for researching GRC IS. As it is more output oriented, goal-setting theory might also be an alternative (Locke et al. 2002). Instead of using theories from management and organizational science, we could also have used theories from computer science or IS which can be extended to accounting information systems as well. For example, the theory of technology dominance (Arnold et al. 1998) might also help in assessing the impact of IT on control especially in terms of decision support. We also focused on exploiting existing control potentials. 
We focused on GRC solutions for control automation and coherence and hence lack a self-contained perspective on exploration.

\section{Conclusion}

In this paper, we ask the research question how IT changes organizational control design. We examined the prominent control trend GRC to answer the research question. We provided evidence that IT-enabled controls within GRC IS change organizational control design. We extend organizational control theory by proposing a new control mechanism called risk control. Risk control enables organizations to prevent possible major negative consequences at an early stage of the value creation process. It allows reduction in variance and performance-steadiness through ubiquitous monitoring of agents. Risk control allows managers to react early and possibly prevent major negative consequences at an early stage of the process. It helps managers to interpret weak signals but requires a high degree of interpretation and the ability to deal with high amounts of data.

\section{References}

Ansoff, H.I.: Managing strategic surprise by response to weak signals. California Management Review 18(2), 21-33 (1975)

Arnold, V., Sutton, S.G.: The Theory of Technology Dominance: Understanding the Impact of Intelligent Decisions Aids on Decision Makers' Judgments. Advances in Accounting Behavioral Research 1, 175-194 (1998)

Ashbaugh-Skaife, H., Collins, D., Kinnery, W.R.: The effect of SOX internal control deficiencies and their remediation on accrual quality. The Accounting Review 83(1), 217-250 (2008)

Beneish, M., Billings, M., Hodder, L.: Internal control weaknesses and information uncertainty. The Accounting Review 83(3), 665-703 (2008)

Cardinal, L.B., Sitkin, S.B., Long, C.P.: Balancing and Rebalancing in the Creation and Evolution of Organizational Control. Organization Science 15, 411-431 (2004)

Chambers, E.G., Foulon, M., Handfield-Jones, H., Michaels, E.G.: War for Talent. McKinsey Quarterly 3, 44-58 (1998)

Chan, Y.E.: Why haven't we mastered alignment? The importance of the informal organization structure. MIS Quarterly Executive 1(2), 97-112 (2002)

Clegg, S.: Foucault, Power and Organization. In: McKinley, A., Starkey, K. (eds.) Foucault, Management and Organization Theory, pp. 29-48. Sage, London (1998)

Das, T., Teng, B.: Trust, control, and risk in strategic alliances: An integrated framework. Organization Studies 22(2), 215-283 (2001)

Davenport, T.H.: Process innovation: reengineering work through information technology, p. 365. Harvard Business School Press, Boston (1993)

Dittmar, L.: Demystifying GRC. Business Trends Quarterly 4, 16-18 (2007)

Doyle, J., Ge, W., Mcvay, S.: Determinants of weaknesses in internal control over financial reporting. Journal of Accounting and Economics 44(1-2), 193-223 (2007)

Eisenhardt, K.M.: Control: Organizational and Economic Approaches. Management Science 31(2), 134-149 (1985) 
Fisher, J.: Compliance in the Performance Management Context: What technologies could simplify compliance and automate information gathering? Bank, Accounting \& Finance 20(4), 41-49 (2007)

Foucault, M.: Discipline and Punishment: The Birth of the Prison, p. 318. Vintage, New York (1977)

Glaser, B.G., Strauss, A.L.: The discovery of grounded theory: Strategies for qualitative research. Aldine de Gruyter, Hawthorne (2001)

Gunge, S.P.: Business Process Reengineering and The New Organization. In: Knights, D., Willmott, H. (eds.) The Reengineering Revolution: Critical Studies of Corporate Change, pp. 114-133. Sage, London (2000)

Hammer, M., Champy, J.: Reengineering the corporation: A manifesto for business revolution. Harper Business, New York (1993)

Heiser, J.: Hype Cycle for Governance, Risk and Compliance Technologies (2010)

Jensen, M.: The modern industrial revolution, exit, and the failure of internal control systems. Journal of Finance 48(3), 831-880 (1993)

Kirsch, L.J., Sambamurthy, V., Ko, D.-G., Purvis, R.L.: Controlling Information Systems Development Projects: The View from the Client. Management Science 48, 484-498 (2002)

Kirsch, L.S.: Portfolios of Control Modes and IS Project Management. Information Systems Research 8(3), 215-239 (1997)

Lange, D.: A Multidimensional Conceptualization of Organizational Corruption Control. The Academy of Management Review 33(3), 710 (2008)

Liu, L., Yetton, P., Sauer, C.: A normative theory of organizational control: Main and interaction effects of control modes on performance. In: Proceedings of the18th European Conference on Information Systems (ECIS), Verona, Italy (2010)

Locke, E.A., Latham, G.P.: Building a Practically Useful Theory of Goal Setting and Task Motivation. American Psychologist 57(9), 705-717 (2002)

Meiselman, J.: Risk, Governance and Compliance Trends for 2007. Risk Management 54(2), 40 (2007)

Nilakant, V., Rao, H.: Agency Theory and Uncertainty in Organizations: An Evaluation. Organization Studies 15(5), 649-672 (1994)

Nixon, W., Burns, J.: Management control in the 21st century. Management Accounting Research 16(3), 260-268 (2005)

Nolan, R., McFarlan, F.W.: Information technology and the board of directors. Harvard Business Review 83(10), 96-106 (2005)

Orlikowski, W.: Integrated Information Environment or Matrix of Control? The Contradictory Implications of Information Technology. Accounting, Management, and Information Technologies 1(1), 9-42 (1991)

Ouchi, W.G.: A Conceptual Framework for the Design of Organizational Control Mechanisms. Management Science 25(9), 833-848 (1979)

Parry, E.: SOX Wars: CIOs share ideas, fears on Sarbanes-Oxley compliance, SearchCIO.com:7 (2004)

Quattrone, P., Hopper, T.: A 'time-space odyssey': management control systems in two multinational organisations. Accounting, Organizations and Society 30(7-8), 735-764 (2005)

Racz, N., Weippl, E., Seufert, A.: A Frame of Reference for Research of Integrated Governance, Risk and Compliance (GRC). In: Communications and Multimedia Security, pp. 106-117. Springer, Heidelberg (2010)

Sia, S., Tang, M., Soh, C., Boh, W.: Enterprise resource planning (ERP) systems as a technology of power: empowerment or panoptic control? ACM SIGMIS Database 33(1), 23-37 (2002)

Strauss, A., Corbin, J.: Basics of Qualitative Research Techniques and Procedures for Developing Grounded Theory Sage. Sage, London (1998) 
Tannenbaum, A.S.: Control in Organizations: Individual Adjustment and Organizational Performance. Administrative Science Quarterly 7(2), 236 (1962)

Volonino, L., Gessner, G.H., Kermis, G.F.: Holistic Compliance with Sarbanes-Oxley. Communications of the Association for Information Systems 14 (2004)

Wagner, S., Dittmar, L.: The unexpected benefits of Sarbanes-Oxley. Harvard Business Review 84(4), 133 (2006)

Walsh, J.P., Meyer, A.D., Schoonhoven, C.B.: A Future for Organization Theory: Living in and Living with Changing Organizations. Organization Science 17(5), 657-671 (2006)

Weick, K.E., Sutcliffe, K.M.: Managing the Unexpected: Assuring High Performance in an Age of Complexity. John Wiley and Sons, San Francisco (2007)

Wiesche, M., Berwing, C., Schermann, M., Krcmar, H.: Patterns for Understanding Control Requirements for Information Systems for Governance, Risk Management, and Compliance (GRC IS). In: CAiSE Workshop on GRCIS, London, UK (to appear, 2011)

Yin, R.K.: Case Study Research: Design and Methods, 5th edn. SAGE Publications, Thousand Oaks (2008) 